
\title{
CIÊNCIANATURA
}

\section{Alterações no Uso da Terra da Bacia Hidrográfica da UHE Salto do Rio Verdinho, Goiás, Brasil}

\author{
Changes in Land Use of the Hydrographic Basin of the HPP Salto do Rio Verdinho, Goiás, Brazil
}

\author{
Isabel Rodrigues Rocha ${ }^{1}$ e João Batista Pereira Cabral ${ }^{2}$ \\ ${ }^{1}$ Doutoranda em Geografia do Programa de Pós-Graduação em Geografia - UFG, Brasil \\ isabel8720@gmail.com \\ ${ }^{2}$ Docente da Universidade Federal de Goiás, Orientador no Programa de Pós-Graduação em Geografia - Regional Jataí- GO, \\ Brasil \\ jbcabral2000@yahoo.com.br
}

\begin{abstract}
Resumo
O modelo de Uso da Terra no Bioma Cerrado passou por grandes alterações a partir da década de 70, ficando bem evidente, após implantações de programas e planos de políticas governamentais, que concederem incentivos para transformar esses cenários. Deste modo, a presente pesquisa teve como objetivo verificar as alterações no uso das terras na bacia de contribuição do reservatório da Usina Hidrelétrica (UHE) Salto do Rio Verdinho, visando identificar as alterações ocorridas antes e após a construção do empreendimento hidrelétrico em questão. A avaliação do uso e ocupação se procedeu em três periodos distintos (nos anos de 2005, 2010 e 2015). O mapeamento de Uso da Terra foi elaborado com apoio de técnicas de geoprocessamento, sendo utilizada a classificação supervisionada, a partir do classificador MaxVer. Para avaliar a qualidade dos mapeamentos, aplicou-se o coeficiente kappa. Conclui-se que, nos últimos 15 anos, a paisagem da bacia apresentou mudanças, onde as pastagens predominam com $55 \%\left(543 \mathrm{~km}^{2}\right)$ da área mapeada em 2015 , mas já ocupou $82 \%\left(806 \mathrm{~km}^{2}\right)$ no ano de 2005. As alterações ocorreram principalmente convertendo-se áreas de pastagens em áreas de agriculturas, devido a expansão da atividade canavieira em 2015. A implantação do lago artificial para produção de energia hidroelétrica foi outro fator que alterou o uso da terra, e por consequência ocasionou a eliminação de áreas de APPs próximas do reservatório.
\end{abstract}

Palavras-chave: Geoprocessamento. Alterações na Paisagem. Uso da Terra

\section{Abstract}

The Land Use model in the Cerrado Biome went through great major changes from the decade 70s, becoming evident, after the implementation of programs and government policy plans, that provide incentives to transform these scenarios. Thus, the present research had as objective to verify the changes in the land use in the basin of contribution of the reservoir of the Salto do Rio Verdinho Hydro Power Plant (HPP), aiming in order to identify the changes that occurred before and after the construction of the hydroelectric development in question. The evaluation of the use and occupation if proceeded in three different periods (in the years 2005, 2010 and 2015). The mapping of Use of Land was elaborated with support of geoprocessing techniques, being used the supervised classification, from the MaxVer classifier. To evaluate the quality of the mappings, the kappa coefficient was applied. It is concluded that, in the last 15 years, the landscape of the basin presented changes, where the pastures predominate with $55 \%\left(543 \mathrm{~km}^{2}\right)$ of the area mapped in 2015, but already occupied $82 \%\left(806 \mathrm{~km}^{2}\right)$ in the year of 2005 . The changes occurred mainly by converting pasture areas in agricultural areas due to the expansion of sugarcane activity in 2015. The implantation of the artificial lake for the production of hydroelectric power was another factor that altered the land use, and consequently caused the elimination of the APPs areas next to the reservoir.

Keywords: Geoprocessing. Landscape Changes. Land Use. 


\section{Introdução}

A partir da década de 70 do século XX, adveio uma evolução no uso da terra no Bioma Cerrado, sobretudo, após políticas governamentais de incentivos agropecuários, que passaram a intervir decisivamente na modernização agrícola da Região Centro-Oeste (CASTRO et al., 2010; DOMINGUES; BERMANN, 2012; SANO et al., 2007).

Segundo informações da EMBRAPA (2015), a partir de 1970, os programas e planos das políticas governamentais, contaram com investimentos para numerosos setores da economia agrícola, e as políticas visavam à introdução de técnicas mais eficientes e modernas para o período.

Conforme Ganem et al. (2013), o bioma Cerrado perdeu 48,2\% de sua cobertura da biomassa original, sendo essas áreas convertidas em outros usos. E em pesquisas de Borges et al. (2016), os resultados apontam que os efeitos do esforço de criação de unidades de conservação neste ambiente são poucos, pois apenas 3,1\% do bioma estão protegidos em unidades de proteção integral.

Os impactos ambientais sofridos pelo processo de antropização, devido ao modelo de Uso da Terra, podem ser mitigados por meio de monitoramento, utilizando informações espaços-temporais, com apoio de imagens de satélites para avaliar as transformações ocorridas na paisagem (CABRAL et al., 2011; COELHO et al., 2014).

Assim, é importante a realização de estudos que analisem os fatores que influenciam o avanço do processo de uso e ocupação das terras em bacias hidrográficas, e que detectem as mudanças sofridas e os seus impactos no solo, principalmente, para que possa servir de subsídios para o planejamento e gestão dos recursos naturais.

Diante das observações destacadas nos parágrafos anteriores, o ambiente da bacia hidrográfica da Usina Hidrelétrica (UHE) Salto do Rio Verdinho, localizada no sul do estado de Goiás, é um local importante para avaliação de estudos de impactos ambientais em escala espaço-temporal, pois, essa bacia vem sofrendo mudanças no uso e ocupação nos últimos anos, conforme está destacado em estudos realizados por THEMAG (2004), CONSILIU (2009), Cabral et al. (2011), Santos et al. (2013).

As áreas da bacia em pesquisa tem sido convertida nesses últimos anos, em diversos usos, para pastagens, e atualmente algumas áreas estão sendo convertidas em áreas de agricultura mecanizada, e ainda foi implantado um reservatório de Usina Hidrelétrica.

Segundo Araujo e Fonseca (2016), é importante realizar uma análise multitemporal, que possibilite comparar uma mesma paisagem entre dois ou mais períodos, auxiliando no monitoramento das suas dinâmicas naturais e antrópicas.

Assim, a presente pesquisa teve como objetivo classificar os usos das terras na bacia de contribuição do reservatório da Usina Hidrelétrica (UHE) Salto do Rio Verdinho, visando identificar as alterações ocorridas antes e após a construção do empreendimento hidrelétrico em questão.

\section{Material e Métodos}

\subsection{Localização da área de estudo}

A bacia hidrográfica do reservatório da UHE Salto do Rio Verdinho (Figura 1) compreende $983 \mathrm{~km}^{2}$ e está localizada próxima à foz da bacia hidrográfica do rio Verde, afluente do rio Paranaíba, rio com grande potencial hidrelétrico no estado de Goiás. A área fica situada na microrregião de Quirinópolis, limitando os municipais de Caçu (margem direita) e Itarumã (margem esquerda). 


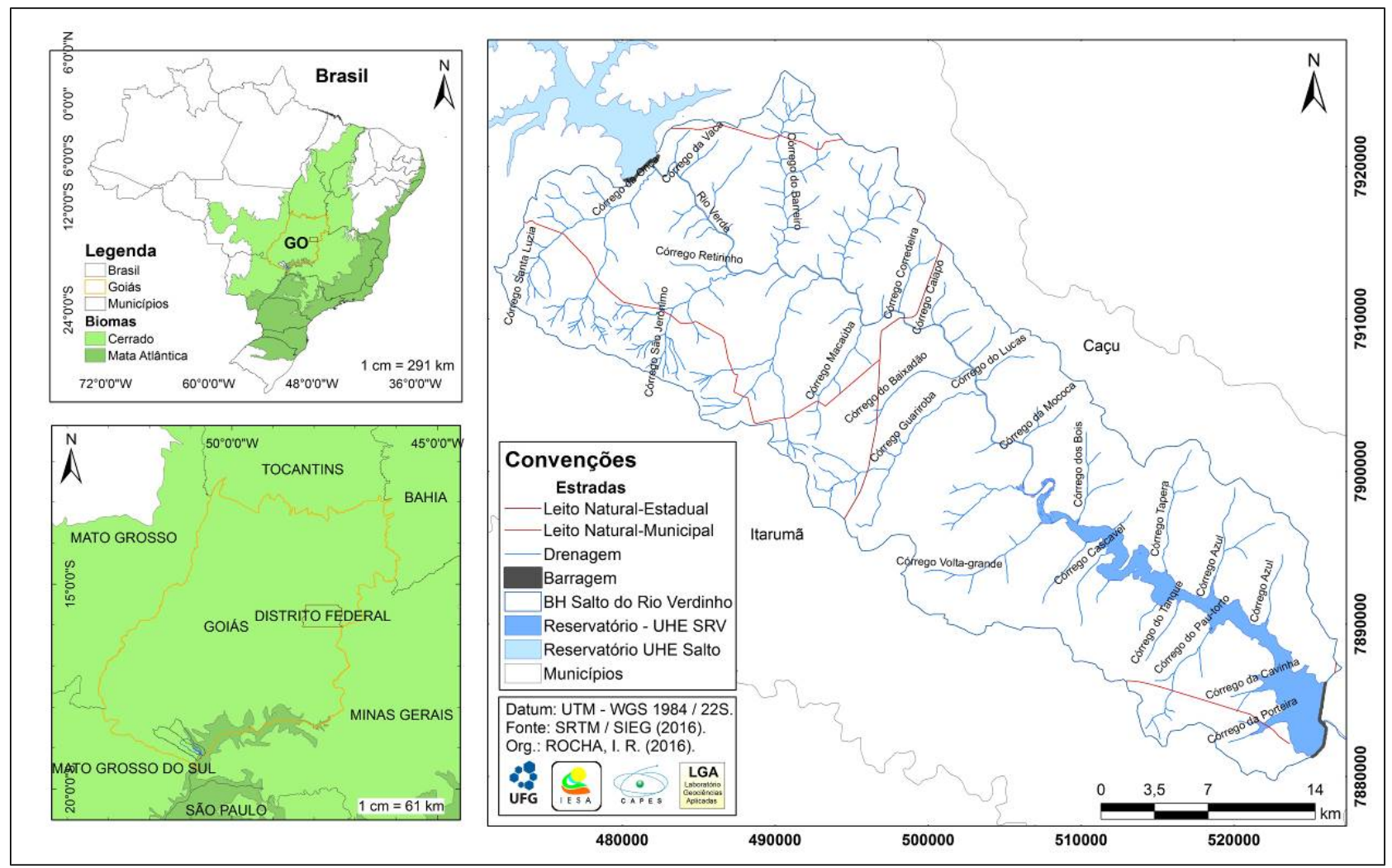

Figura 1 - Localização da bacia hidrográfica da UHE Salto do Rio Verdinho. Fonte: SRTM/SIEG, 2016. Organização: ROCHA, I. R., 2016.

A bacia encontra-se em ambiente com duas estações climáticas distintas, com características de verão chuvoso e inverno seco, parecidos em toda região central do Brasil (AYOADE, 1998).

Segundo Nimer (1989), o fator climático que mais afeta a região central brasileira é a pluviosidade das chuvas, intensa durante o verão, com um clima com característica de tropical chuvoso (Aw), segundo classificação de Köppen. Em contra partida, a temperatura não é uma determinante, porque não varia muito durante o ano, mas, possui função estabilizadora.

O índice pluviométrico chega até $1600 \mathrm{~mm}$ por ano e estão concentrados durante a estação chuvosa, a temperatura média anual é de $22^{\circ} \mathrm{C}$ (MARIANO, et al., 2003).

Nesse sentido, é importante destacar, que a bacia em pesquisa está em área de transição do Bioma Cerrado para o de Mata Atlântica, o que caracteriza um ambiente muito importante para compreensão da dinâmica vegetal, e, de uso e ocupação dos ambientes dos biomas em conjunto.

\subsection{Processamento Cartográfico e Banco de dados}

O mapeamento do uso da terra foi realizado em intervalos de cinco anos (Tabela 1), com intuito de compreender as alterações antes (Ano de 2005), durante (Ano de 2010) e após (Ano de 2015) a construção do reservatório da UHE Salto do Rio Verdinho. Foram utilizadas imagens dos satélites Landsat 5 - Sensor TM (Thematic Mapper) e do Landsat 8 - Sensor OLI (Operational Land Imager), disponibilizadas pelo Instituto Nacional de Pesquisas Espaciais (INPE) e no site do Serviço Geológico dos Estados Unidos (United States Geological Survey - USGS). 
Tabela 1- Datas das imagens dos satélites Landsat 5 e 8, selecionadas para o estudo

\begin{tabular}{c|c|c|c}
\hline \multirow{2}{*}{ Orbita e cena das imagens } & \multicolumn{3}{|c}{ Satélites e Passagens } \\
\cline { 2 - 4 } & \multicolumn{2}{|c}{ Landsat 5- Sensor } & $\begin{array}{c}\text { Landsat 8 - Sensor } \\
\text { TM }\end{array}$ \\
\cline { 2 - 4 } & 2005 & 2010 & 2015 \\
\hline $222 / 73$ & $30 / 07 / 2005$ & $12 / 07 / 2010$ & $11 / 08 / 2015$ \\
\hline $223 / 73$ & $06 / 08 / 2005$ & $03 / 07 / 2010$ & $02 / 08 / 2015$ \\
\hline
\end{tabular}

Fonte: INPE (2015); USGS (2015). Organização: ROCHA, I. R., 2016.

Para classificar as imagens, seguiram-se alguns procedimentos, a partir de mosaicos de imagens. Os mapeamentos de Uso da Terra foram organizados no software ArcGIS 10.1; A escolha das imagens para os mosaicos compreenderam o mesmo período de análise. A época escolhida foi sazonal de estação seca, pois é a que apresenta menores porcentagens de formação de nuvens e interferência dos efeitos atmosféricos, como de frentes frias e massas de ar (ROSA, 2007).

A classificação utilizada foi a supervisionada, com a utilização do classificador MaxVer, baseando-se no método de ponderação das distâncias entre médias dos níveis digitais das classes, em que a probabilidade de um pixel pertencer ou não à uma determinada classe ou a outra.

As unidades de paisagens identificadas nas áreas da pesquisa seguiram a classificação proposta pelo Sistema básico de classificação da cobertura e do uso da terra (SCUT), prevista no Manual Técnico de Uso da Terra do IBGE, que define os procedimentos metodológicos para elaboração do mapa temático de Uso da Terra (IBGE, 2013). As classes englobaram as seguintes categorias: “Água” no subitem “Águas Continentais”, para a classe $<$ Água >, na categoria de "Áreas de Vegetação Natural” englobou a classe <Vegetação/Cerrados $>$, na categoria “Áreas antrópicas agrícolas" permaneceu a classe presente de $<$ Culturas $>$ e $<$ Pastagens $>$. Portanto, a bacia em estudo situa-se em ambiente de área rural, e as áreas habitadas não tiveram posição representada nos mapeamentos.

Para a análise de exatidão dos mapeamentos foi aplicado o coeficiente kappa, visando confirmar os resultados obtidos nas classificações, pois, nem sempre é atingida com exatidão a realidade do cenário. Porém, é uma ferramenta útil e capaz de auxiliar nas análises ambientais de maneira rápida e com resultados satisfatórios (SILVA et. al., 2016).

Segundo Foody (2002), os resultados são de boa qualidade, obtidos em mapeamentos com o índice kappa expresso na equação (1), podendo se verificar o nível de confiabilidade e exatidão das informações contidas nos mapas.

$$
\mathrm{K}=\frac{N \sum_{i=1}^{r} x_{i i}-\sum_{i=1}^{r}\left(x_{i+*} x_{+1}\right)}{N^{2}-\sum_{i=1}^{r}\left(x_{i+*} x_{+1}\right)}
$$

Onde: $\mathrm{K}=$ Índice Kappa de concordância; $\mathrm{N}=$ Número de observações (pontos amostrais); $\mathrm{r}=$ Número de linhas da matriz de erro; $\mathrm{Xii}=$ Observações na linha i e coluna $\mathrm{i} ; \mathrm{Xi}+=$ Total marginal da linha $\mathrm{i} ; \mathrm{X}+1=$ Total marginal da coluna i.

Facco e Benedetti (2016) indicam que a confiabilidade da classificação digital é avaliada a partir da matriz de confusão das áreas de treinamento das amostras de usos. 
A tabela 2 apresenta a avaliação do índice kappa e a qualidade para cada classificação proposta por Landis e Koch (1977). O Índice de Kappa é avaliado de 0 a 1, e os dados mais apurados quanto a qualidade, é o índice que mais se aproxima de 1. Por conseguinte, para que os dados sejam aceitáveis, Foody (2002) recomenda níveis para melhor exatidão do índice kappa em torno de 0,85 .

Tabela 2 - Referências para classificações de Índice kappa e sua respectiva qualidade

\begin{tabular}{c|c}
\hline Índice kappa & Qualidade \\
\hline 0 & Péssima \\
\hline 0,01 a 0,20 & Ruim \\
\hline 0,21 a 0,40 & Razoável \\
\hline 0,41 a 0,60 & Boa \\
\hline 0,61 a 0,80 & Muito Boa \\
\hline 0,81 a 1,00 & Excelente \\
\hline
\end{tabular}

Fonte: Landis e Koch (1977). Organização ROCHA, I. R., 2016.

\section{Resultados e Discussão}

\subsection{Processamento Cartográfico e Banco de dados}

A partir da análise espaço-temporal de uso da terra na bacia hidrográfica da UHE Salto do Rio Verdinho foi possível observar na figura 2 (A), (B) e (C), que ocorreram mudanças com relação ao modelo de uso da terra nos três períodos (Anos de 2005, 2010 e 2015) de análises.

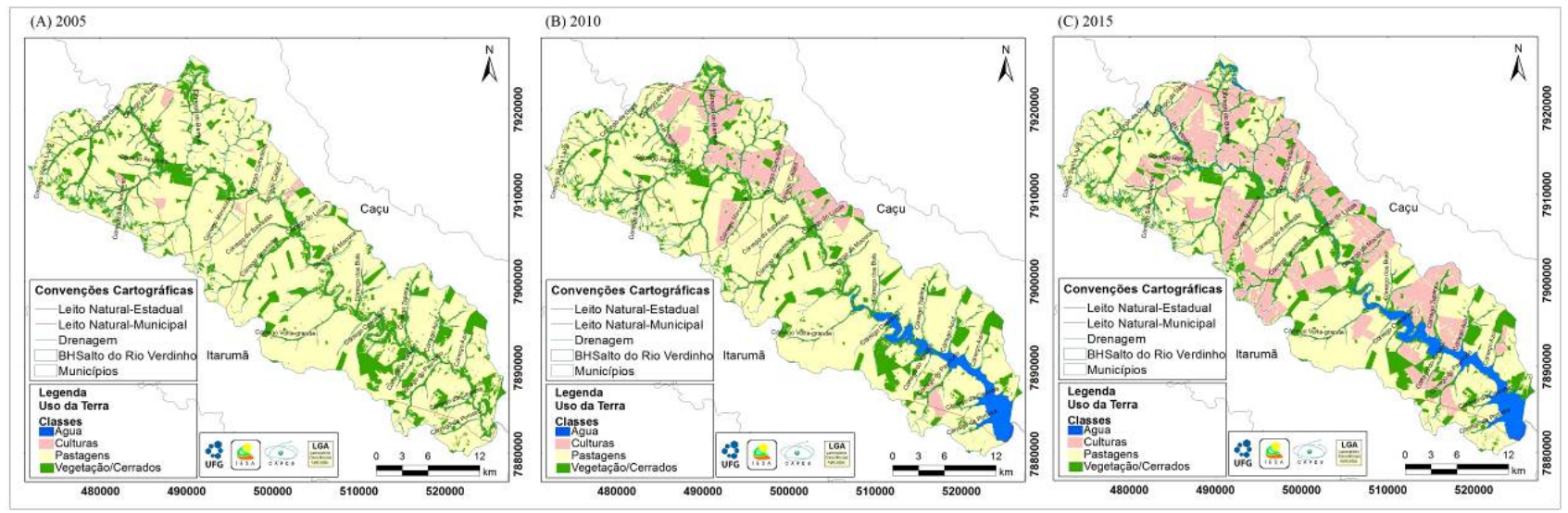

Figura 2 - Mapas de Usos das Terras de 2005, 2010 e 2015 da bacia hidrográfica da UHE Salto do Rio Verdinho. Organização: ROCHA, I. R., 2016.

No ano de 2005 (Figura 2 - A), ocorreu o predomínio da classe Pastagens, o que é legitimado pelos processos históricos de ocupação do centro-oeste, com a adoção do modelo pastoril. A pastagem se incorpora à paisagem a partir do desenvolvimento da economia na região (SANO et al., 2007). 
A partir da instalação de novos complexos agroindustriais, as atividades de pastagem cedem espaço para as atividades agropastoris (Figura 2 - B) e um empreendimento hidráulico, a partir da construção da UHE Salto do Rio Verdinho.

As áreas destinadas às culturas de lavouras temporárias se destacam em 2015 (Figura 2 - C), com maior ocupação do que nos últimos 10 anos. Tanto a margem esquerda quanto a margem direita da bacia contribuinte da UHE, vem sendo alteradas.

A ocupação de cana-de-açúcar foi evidenciado nos mapeamentos de Uso da Terra em maior escala a partir do ano de 2010, devido à implantação de indústrias sucroalcooleiras na região, com distância de $30 \mathrm{a} 40 \mathrm{~km}$ das áreas de plantio, próximas a UHE Salto do Rio Verdinho. A ETH Unidade Rio Claro (Figura 3) localiza-se no município de Caçu (GO), e já está consolidada desde agosto de 2009, de acordo com a empresa construtora LMR Engenharia LTDA (2016).

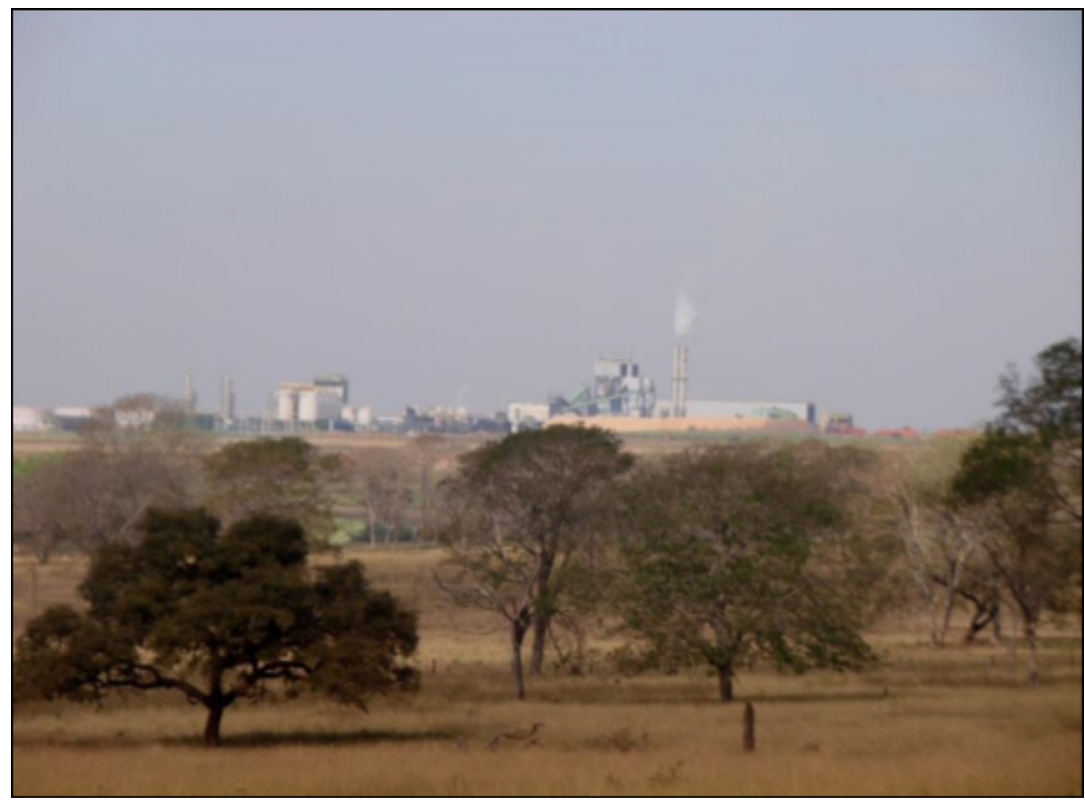

Figura 3 - Usina ETH Bioenergia S/A, Unidade Rio Claro, município de Caçu - GO. Fonte: LIMA (2013).

A ocupação da cana-de-açúcar na área de influência da bacia do UHE Salto do Rio Verdinho é recente, mas alterou extensões significativas de pastagens. Segundo Santos et al. (2013) foram observados no projeto PACUERA (Plano Ambiental de Conservação e Uso do Entorno do Reservatório Artificial) que, entre as culturas presentes, a cana-deaçúcar era a de maior extensão, seguida de silviculturas em locais isolados.

Com à análise temporal do uso da terra, as Áreas de preservação permanente (APP) cedem espaço para a classe água, observando-se a partir do atual local do reservatório, que anteriormente era composto por áreas de vegetação de matas ciliares. A fase final do enchimento do reservatório foi concretizada no ano de 2010 .

Ao avaliar o EIA/RIMA (THEMAG, 2004) da UHE Salto do Rio Verdinho, observou-se que levariam em consideração a retirada da vegetação do leito do rio, como é feito em todo empreendimento hidrelétrico, mas foi verificado nos mapas de 2010 e 2015, que não foram consideradas nos planejamentos prévios do projeto, que essas áreas seriam alagadas. 
A partir da análise do mapeamento do uso da terra de 2015 e visita a campo, se verificou o que resta dessas antigas vegetações de matas ciliares nas áreas de APPs, e são esqueletos de arvores no lago, como pode ser observado na figura 4.

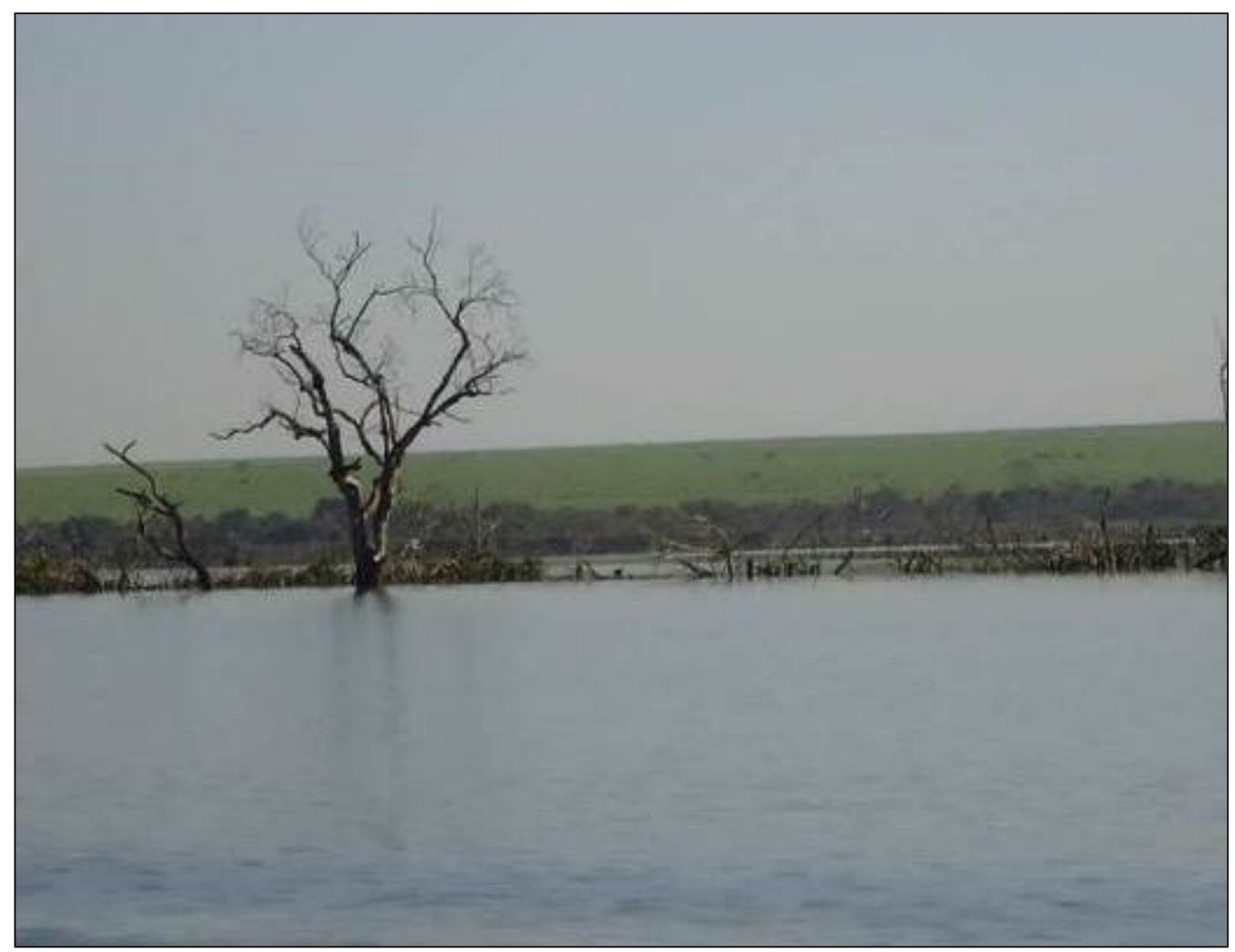

Figura 4 - Paisagem que contempla a água e antigas matas ciliares inundadas, e extensa área de cultura.

Fonte: ROCHA, I. R., 2015.

As áreas de APPs deveriam ser reflorestadas no entorno de 15 metros de distância das margens do reservatório, amparadas segundo disposições que definem limites para as APPs, prevista na resolução CONAMA No 303/02, de 20 de março de 2002 para reservatórios artificiais (BRASIL, 2002).

A aplicação de replantio de mata ciliar em reservatório deve consentir em gerar proteção contra o uso e exploração das águas pelos proprietários rurais para dessedentação animal e pesca exploratória. O rebanho deve ser dessedentado com água canalizada segundo Carneiro et al. (2010).

$\mathrm{Na}$ figura 5, pode ser observado, que as margens próximas da barragem encontram-se sem proteção, sem a presença de áreas de APPs, que previnem a entrada direta do gado para o acesso à dessedentação, comprovando que ainda não está sendo implantado no reservatório da UHE Salto do Rio Verdinho o projeto de reflorestamento das APPs de acordo com a resolução CONAMA 303/02. Assim, como também foi observado por CONSILIU (2009), o acesso livre do gado direto à água em algumas margens.

As ocupações tiveram significativas mudanças nos últimos 15 anos, nos três intervalos de diagnóstico. Visto que, na região é comum a rotação das atividades de agricultura substituindo áreas de atividade pecuária. O domínio da paisagem da bacia permanece com extensas áreas de culturas e pastagens. 


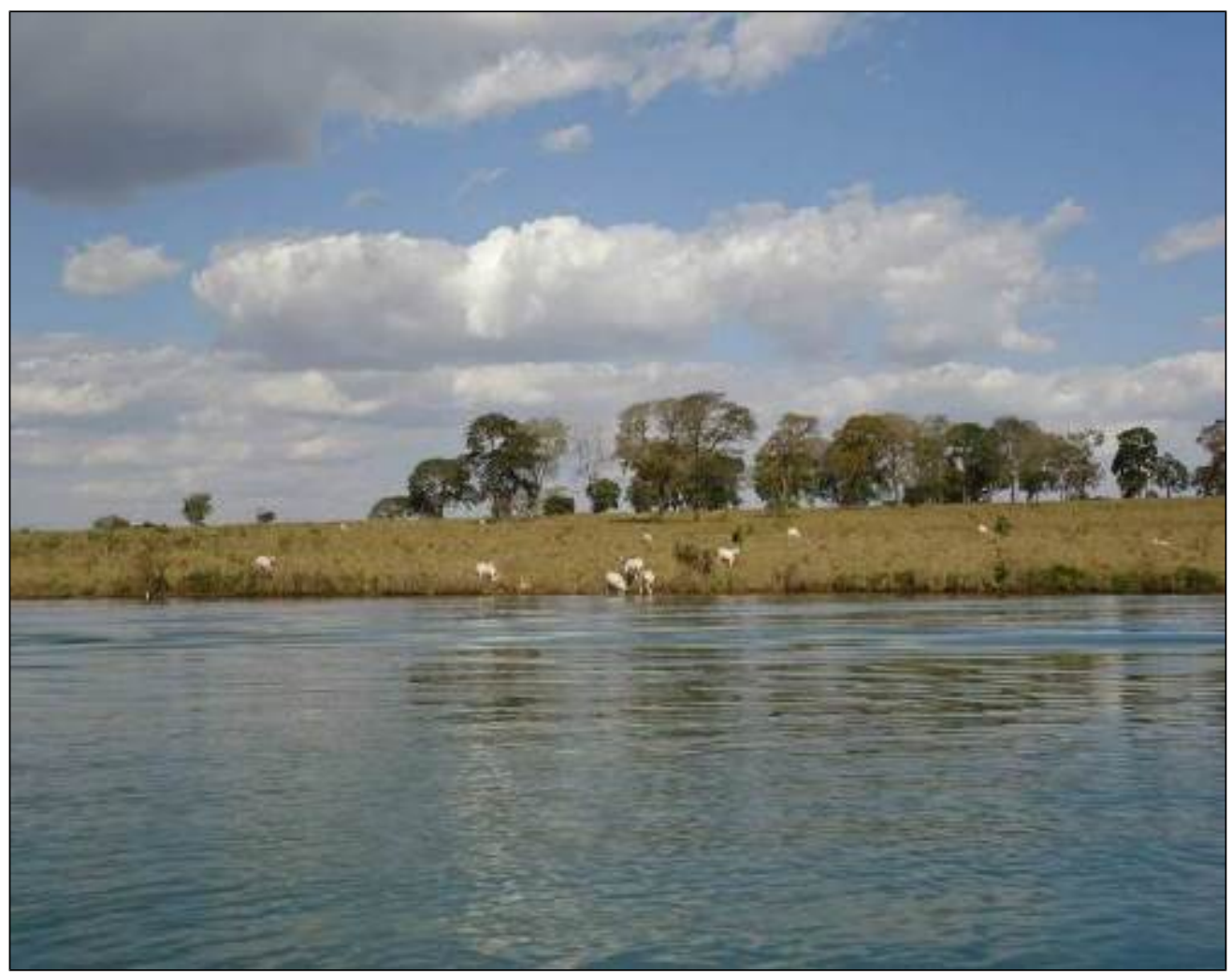

Figura 5 - Paisagem da ocupação de pastagens para pecuária de corte as margens do reservatório. Fonte: ROCHA, I. R., 2015.

3.2. Alterações dos Usos das Terras entre os anos de 2005, 2010 e 2015

Tabela 3 - Cálculo de áreas das classificações de Usos das Terras, dos anos de 2005, 2010 e 2015

\begin{tabular}{l|c|c|c}
\hline \multirow{2}{*}{ Classes de Uso } & 2005 & 2010 & 2015 \\
\cline { 2 - 4 } & $\mathrm{km}^{2}$ & $\mathrm{~km}^{2}$ & $\mathrm{~km}^{2}$ \\
\hline Água & 10,58 & 32,56 & 48,73 \\
\hline Culturas & 7,71 & 81,23 & 237,4 \\
\hline Pastagens & 806,37 & 714,4 & 546,21 \\
\hline Vegetação/Cerrados & 158,65 & 155,68 & 150,89 \\
\hline TOTAL & 983,31 & 983,47 & 983,23 \\
\hline
\end{tabular}

Organização: ROCHA, I. R., 2016.

Conforme a pesquisa de May e Reis (2016), com objetivo de verificar a expansão ou retração agrícola no município de Centenário, RS, no período de 1995-2014, tiveram resultados com significativa expansão agrícola e uma consequentemente retração das áreas de floresta e áreas de campo, conferindo resultados similares ao presente artigo, demonstrando que agricultura expandiu em todos os períodos na bacia da UHE Salto do Rio Verdinho. 


\subsection{Qualidade dos mapeamentos (Índice Kappa)}

No intuito de verificar a qualidade das classificações, os resultados da aplicação do coeficiente kappa podem ser observados na tabela 4. As classificações, demostraram índice kappa enquadrados em todos os anos de análises na classe excelente, com valores acima de 0,90, nível maior que o sugerido por Foody (2002).

A partir da análise da tabela 3, verifica-se que é evidente as alterações nos usos das diversas áreas da bacia, em um intervalo de 15 anos. Pois, se percebe as diferenças ocorridas em relação às áreas remanejadas de anos anteriores.

Em 2005 a classe pastagem ocupava $806,37 \mathrm{~km}^{2}$ da área da bacia, em 2010 a área ocupada pela pastagem passa ser de 714,4 km², e, em 2015 essa mesma classe ocupava 546,21 km².

Houve um crescimento das atividades agrícolas no entorno da bacia no ano de 2010 de $73,52 \mathrm{~km}^{2}$ em relação ao ano de 2005, sendo um crescimento de $156,17 \mathrm{~km}^{2}$ em 2015 em relação ao ano de 2010. Entre os usos que cederam áreas para a agricultura até 2015 , estão as áreas de pastagens.

A Classe água aumentou 21,98 km² em relação ao ano de 2005, e no ano de 2015 aumentou $16,17 \mathrm{~km}^{2} \mathrm{em}$ relação ao ano de 2010. A classe Pastagens, bem como a Vegetação/Cerrados cederam áreas para a classe água, representada pelo alagamento do reservatório artificial no ano de 2010.

No mapeamento de 2015, somadas, as pastagens e as culturas cobrem cerca $80 \%$ da área da bacia. Assim, $30 \%$ são equivalente as classes Vegetação/Cerrados e água.

Foody (2002), com índice kappa acima de 0,85, para melhor exatidão nos mapas. Ou seja, os mapas contêm apenas $7 \%$ de erros de confusão.

Tabela 4 - Enquadramento do Índice de kappa e as respectivas qualidades dos resultados de uso e ocupação da terra dos anos de 2005, 2010 e 2015 em análise

\begin{tabular}{c|c|c|c}
\hline & 2005 & 2010 & 2015 \\
\hline Índice kappa & 0,92 & 0,92 & 0,93 \\
\hline Qualidade & Excelente & Excelente & Excelente \\
\hline
\end{tabular}

Organização: ROCHA, I. R., 2016.

Foram elaboradas matrizes de erros de dados temáticos geradas para os mapeamentos. Pois, as mudanças foram significativas nos usos em várias áreas da bacia, o total de amostragens cobriu todas as áreas que compõem as alterações decorrentes, como de áreas de pastagens por culturas. Deste modo, quanto maior o número de amostras, mais significativo será o resultado do coeficiente.

Assim, a excelência do resultado obtido com o índice kappa ficou a cargo do classificador e do software utilizado, pois, a cada ano, novas versões são publicadas visando melhoria nas ferramentas de SIGs. A realização de trabalho de campo é sempre essencial na compreensão da realidade do Uso da Terra, facilitando a elaboração de mapas temáticos. 


\section{Conclusões}

A observação aplicada possibilitou verificar que as mudanças no Uso da Terra de 2005 a 2015 ficaram a cargo da inserção das atividades agrícolas da cana-de-açúcar, além das agropecuárias já existentes, qual cederam áreas para a agricultura.

De acordo com os resultados obtidos dos mapas, verificou-se que a realidade de uso da bacia foi predominante

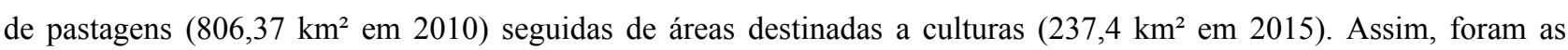
classes de culturas e pastagens que mais variaram nos mapeamentos, e os níveis de diferenças foram: à classe Pastagens era a principal ocupação em 2005, e em 2015 à mesma teve que dividir suas áreas com à classe de Culturas foi a mais expressiva.

Entre as culturas produzidas na bacia, foi identificada que a cana-de-açúcar é a principal, e é recente, desde o ano de 2010, onde vêm alterando extensões significativas de pastagens. Isso porque, próximo à área de influência da bacia do UHE Salto do Rio Verdinho, está implantada uma usina sucroalcooleira no município de Caçu, margem esquerda do reservatório.

Outro uso que sofreu expressiva alteração, foi o volume de água represado para implantação do reservatório artificial, para implantação de usina hidroelétrica, que absorveu áreas da classe de Vegetação/Cerrados, notadamente pelas fotos representativas da região.

\section{Agradecimentos}

Agradeço ao Laboratório de Geociências Aplicadas (LGA) da UFG (Universidade Federal de Goiás). E em especial a CAPES (Coordenação de Aperfeiçoamento de Pessoal de Nível Superior) que fornece bolsa de estudo de nível de doutorado.

E, ao Programa de Cooperação Acadêmica (Procad), pelo financiamento de parte da pesquisa através do Processo 88887.124105/2014-00, projeto: Análise integrada em bacias hidrográficas: estudos comparativos com distintos usos e ocupações do solo.

\section{Referências}

ARAUJO, T. D. FONSECA, E. L. Análise multitemporal dos Lençóis Maranhenses entre 1984 a 2014 utilizando sensoriamento remoto orbital. Revista Brasileira de Geografia Física. V. 09 N. 01, 2016, p. 280-295. Disponível em: $<$ http://www.revista.ufpe.br/rbgfe/index.php/revista/article/view/1456/915> Acesso em: 10 dez. 2016.

AYOADE, J. O. Introdução à climatologia para os trópicos. 13. ed. Rio de Janeiro: Bertrand Brasil. 1998. p.138-144.

BORGES, P. P., MARTINS, P. T. A., FERREIRA, A. A. Uso e ocupação do solo por meio de uma série histórica na bacia do rio Santa Teresa em Goiás. Revista Brasileira de Geografia Física V. 09 N. 01, 2016, p. 296-304. Disponível em: <http://www.revista.ufpe.br/rbgfe/index.php/revista/article/view/1496/916> Acesso em: 10 dez. 2016.

BRASIL. Ministério do Meio Ambiente, Conselho Nacional do Meio Ambiente. Resolução CONAMA n 303 de 20 de março de 2002. Brasília, 2002. Disponível em: <http://www.mma.gov.br/port/conama/res/res02/res30302.html> Acesso em: 10 mar. 2015. 
CABRAL, J. B. P., ROCHA, I. R., MARTINS, A. P., da ASSUNÇÃO, H. F. e BECEGATO, V. A. Mapeamento da fragilidade ambiental da bacia hidrográfica do Rio Doce (GO), utilizando técnicas de geoprocessamento. GeoFocus (Artículos), no 11, 2011, p. 51-69. Disponível em: <http://geofocus.rediris.es/2011/Articulo3_2011.pdf > Acesso em: 08 ago. 2015.

CASTRO, S. S.; ABDALA, K.; APARECIDA SILVA, A.; BORGES, V. A expansão da cana-de-açúcar no cerrado e no Estado de Goiás: Elementos para uma análise espacial do processo. Boletim Goiano de Geografia, v. 30, p. 171-191, 2010.

COELHO, V. H. R. et al. Dinâmica do uso e ocupação do solo em uma bacia hidrográfica do semiárido brasileiro. Revista Brasileira de Engenharia Agrícola e Ambiental, Campina Grande, PB, Vol.18, No.1, p.64-72, 2014. Disponível em: <http://www.scielo.br/pdf/rbeaa/v18n1/v18n1a09.pdf> Acesso em: 08 nov. 2015.

COHEN, J. A coeficient of agreement for nominal scales. Educational and Measurment, New York, v. 20, n. 1, 1960, p. $37-46$.

CONSILIU, Meio Ambiente e Projetos. Plano ambiental de conservação e uso do entorno do reservatório artificial (PACUERA) - UHE Salto do Rio Verdinho. Volume 2: Zoneamento. Jun., 2009.

DOMINGUES, M. S.; BERMANN, C. O arco de desflorestamento na Amazônia: da pecuária à soja. Ambiente \& Sociedade, São Paulo Vol. XV, No. 2, mai.-ago., 2012, p. 1 -22. Diponivel em:

$<$ http://www.scielo.br/pdf/asoc/v15n2/02.pdf $>$ Acesso em: 10 out. 2015.

EMBRAPA, Empresa Brasileira de Pesquisa Agropecuária. Embrapa Cerrados: História. Disponível em: $<$ http://www.cpac.embrapa.br/unidade/historia/> Acesso em: 20 out. 2015.

FACCO, D. S.; BENEDETTI, A. C. A evolução temporal do uso e ocupação da terra em municípios da Quarta Colônia de Imigração Italiana - RS. Ciência e Natura, Santa Maria v.38 n.3, 2016, p. 1254 - 1264. Disponível em: $<\mathrm{http} / / /$ www.scielo.br/pdf/rbeaa/v14n1/v14n01a08.pdf> Acesso em: 10 nov. 2015.

FOODY, G. M. Status of land cover classification accuracy assessment. Remote Sensing of Environment, v. 80, n. 1, p. 185-201, 2002.

GANEM, R. S.; DRUMMOND, J. A.; FRANCO, J. L. de A. Conservation polices and control of habitat fragmentation the Brazilian Cerrado biome. Ambiente \& Sociedade, São Paulo Vol. XVI, No. 3 jul.-set., 2013, p. 99-118. Disponível em: <http://www.scielo.br/pdf/asoc/v16n3/v16n3a07.pdf> Acesso em: 10 nov. 2015.

IBGE. Instituto Brasileiro de Geografia e Estatística. Manual Técnico de Uso da Terra. Ministério do Planejamento, Orçamento e Gestão. Rio de Janeiro: IBGE - Manuais Técnicos em Geociências, nº 7 - $3^{\mathrm{a}}$ ed. Rio de Janeiro, 2013.

INPE. Instituto Nacional de Pesquisas Espaciais-Divisão de Geração de Imagens (DGI-INPE). Catálogo de Imagens. Disponível em: $<$ http://www.dgi.inpe.br/>. Acesso em: 03 jul. 2015.

KLECKA, W. R. Discriminant analysis. Beverly Hills: SAGE, 1980. 71 p.

LANDIS, R.; KOCH, G. G. The measurement of observer agreement for categorical data. Biometrics, v.33, n.1, p.159174, Mar. 1977.

LMR Engenharia LTDA. UHE Salto do Rio Verdinho (93 MW) - Caçú/GO. Itajaí/SC, 2016. Disponível em: $<$ http://www.lmrengenharia.com.br/lmrengenharia.php > Acesso em: 24 jan. 2016.

LIMA, A. M. Relação clima e vegetação na área das bacias das usinas hidrelétricas de Barra dos Coqueiros e Caçu-GO. 89f. Dissertação apresentada ao Programa de Pós-Graduação em Geografia/PPG-GEO Stricto Sensu da Universidade Federal de Goiás - Campus Jataí/CAJ-UFG. GO, Jataí, 2013. Disponível em:

$<$ http://posgeo.jatai.ufg.br/uploads/180/original_Disserta\%C3\%A7\%C3\%A3o_Andreia_Medeiros_de_Lima.pdf $>$. Acesso em: 19 abr. 2015. 
MARIANO, Z. F.; SANTOS, M. J. Z.; SCOPEL, I. Variabilidade e tendência climática da região do Sudoeste de Goiás e sua relação com a cultura da soja. In: Seminário de Pós-Graduação em geografia da UNESP, Anais... Rio Claro: Universidade Estadual Paulista, 2003, v. 1, p. 596-616.

MAY G. C.; REIS, J. T. Análise das alterações do uso e cobertura do solo no município de Centenário-RS com o auxílio do Sensoriamento Remoto, no período de 1995-2014. Ciência e Natura, Santa Maria v.38 n.3, 2016 , p. 1228 1237. Disponível em: <http://www.scielo.br/pdf/rbeaa/v14n1/v14n01a08.pdf> Acesso em: 10 nov. 2015.

NIMER, E. Climatologia do Brasil. Instituto Brasileiro de Geografia e Estatística, Rio de Janeiro, RJ. 421 p. 1989.

RODRIGUES, M. T. et al. Sensoriamento remoto e geoprocessamento aplicado ao uso da terra para avaliação entre classificadores a partir do índice kappa. Revista Científica Eletrônica de Engenharia Florestal, Garça - SP, Vol. 23, No.1, fev, 2014, p. 60-70.

ROSA, R. Introdução ao sensoriamento remoto. Uberlândia: Editora UFU, 2007.

SANO, E. E. et al. Mapeamento de cobertura vegetal do Bioma Cerrado: estratégias e resultados. Planaltina, DF: Embrapa Cerrados, 2007.

SANTOS, D. A. R. et al. Aplicação de Geotecnologias para a elaboração do Plano Ambiental de Conservação e Uso do Entorno do Reservatório Artificial (PACUERA) da UHE Salto do Rio Verdinho/Goiás. In: XVI Simpósio Brasileiro de Sensoriamento Remoto - SBSR, Foz do Iguaçu, PR, Brasil, 2013. Anais... XVI Simpósio Brasileiro de Sensoriamento Remoto - SBSR, Foz do Iguaçu, PR, Brasil, 2013. p. 6548-6555.

SILVA, J. S., SILVA, R. M., SILVA, A. M. Mudanças do uso e ocupação do solo e degradação eco-ambiental usando imagens orbitais: o estudo de caso da bacia do rio Bacanga, São Luís (MA). Revista Brasileira de Geografia Física. V. 09 N. 01, 2016, p. 265-279. Disponível em: <http://www.revista.ufpe.br/rbgfe/index.php/revista/article/view/1291/914> Acesso em: 10 dez. 2016.

TANGERINO, D. F.; LOURENÇO, R. T. Comparação da exatidão de métodos de classificação supervisionada e não supervisionada a partir do índice kappa na micro bacia do Ribeirão Duas Águas em Botucatu/SP. XVI Simpósio Brasileiro de Sensoriamento Remoto - SBSR. 2013, Foz do Iguaçu, PR. Anais... São José dos Campos: INPE, 2013, p. 4093.

THEMAG. Estudo e Relatório de Impacto Ambiental da UHE Salto do Rio Verdinho. THEMAG Energia e gerenciamento LTDA e CTE Centro tecnológico de engenharia LTDA, 2004. 